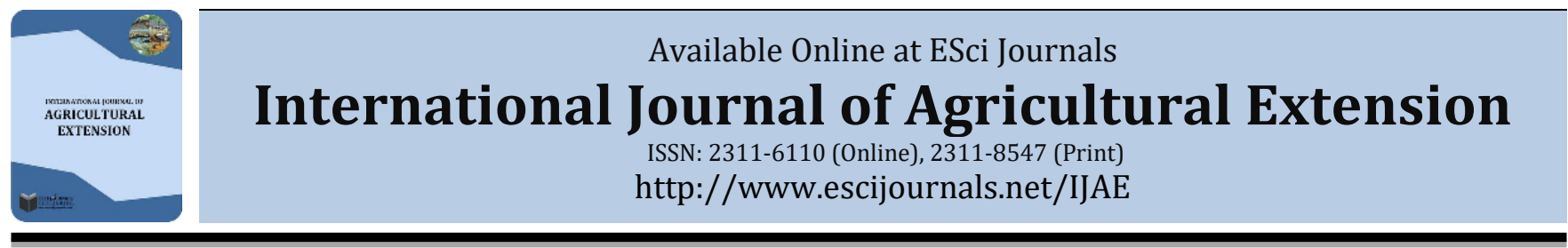

\title{
ASSESSING THE STATUS OF SOCIAL MEDIA FAMILIARITY AMONG SMALLHOLDER FARMERS: A CASE STUDY OF THIKA, KIAMBU KENYA
}

\author{
aAnne W. Kimani, bHillary T. Nyang'anga, bJohn I. Mburu \\ ${ }^{a}$ Kenya Agricultural and Livestock Research Organization-CRI, P.O. Box 4-00232, Ruiru, Kenya. \\ ${ }^{b}$ University of Nairobi, Department of Agricultural Economics, Faculty of Agriculture, Nairobi, Kenya.
}

\section{A B S T R A C T}

Social media provides huge opportunities and incentives that could ease promotion of agricultural extension, facilitate real-time service delivery and enable wider farmer coverage. Ineffective dissemination approaches, expanding farmer population, low staffing, and aging agricultural extension agents continue to negatively affect the provision of agricultural extension services in Kenya. Despite the social media potential in agricultural communication, lack of awareness and low usage in the rural areas of developing countries have been documented. This study sought to establish the level of social media familiarity among smallholder rural farmers with the aim of exploring the possibility of usage in agricultural extension. The study was undertaken in Thika Sub-County of Kiambu County on 140 farmers through a researcher administered semi-structured questionnaire. Probability-proportional-to-size sampling method was employed to derive the sample size from existing extension farmer groups. Simple random sampling technique was further used to identify the actual respondents from each group. A low level of social media familiarity was established among the farmers with education, age and gender having significant influence. The study recommends awareness creation initiatives to promote social media familiarity with a particular focus on women who form the bulk of the farmers but with the lowest level of social media knowledge.

Keywords: Social media, familiarity, agricultural extension, smallholder farmers, information.

\section{INTRODUCTION}

The agricultural sector in Kenya is dominated by smallholder farmers who are concentrated in rural areas (KIPPRA, 2017). Uptake of new agricultural knowledge among farmers is low due to poor linkages between research and extension advisory services (KALRO, 2016). Low staffing, increasing farming population, physical distances to be covered as well as limited access to new information have been listed among major challenges impeding the effectiveness of extension advisory services (GoK, 2012). Wabwoba \& Wakhungu, (2013) report $1: 1500$ as the extension to farmers' ratio in Kenya against the ideal ratio of 1:400 (GoK, 2012). Success in agriculture and rural development is attributed to the action of millions of rural families whose decisions are influenced by the information, knowledge, and technologies at their disposal (FAO, 2015). Social media, a recent addition to

* Corresponding Author:

Email: annkimani09@gmail.com

(C) 2019 ESci Journals Publishing. All rights reserved.
ICTs is transforming the way people find news and information thus enabling the creation of informed rural communities for improved agricultural progress (Jijina \& Raju, 2016). In Africa, where access to agricultural outputs generated in public research organizations is a challenge, social media has the potential to enhance the search for, distribution and sharing of the new technologies (Chisenga, Kedemi, \& Sam, 2014). In Kenya for instance, a number of social media innovations including platforms like Mkulima Young, Young Farmers Market, Digital Farmers Kenya and Mkulima Hub Kenya have been developed with the aim of enhancing agricultural productivity (Kipkurgat, Onyiego, \& Chemwaina, 2016). The platforms are aimed at educating and informing farmers on agricultural related matters through sharing of information links and news articles as well as making inquiries and obtaining feedback (Kipkurgat, Onyiego, \& Chemwaina, 2016). In addition to the platforms mentioned above, most agricultural institutions in Kenya have incorporated social media as 
part of their information systems. The Kenya Agricultural and Livestock Research Organization and the Agricultural Information Resource Center for example use, Twitter, YouTube, and Facebook platforms as well as blogs. However, low social media usage among farmers has been attributed to lack of awareness (Rhoades \& Aue, 2010). The study objective was therefore to assess the status of social media familiarity among smallholder farmers in Thika Sub-county of Kiambu in Kenya with the aim of understanding whether they were likely to benefit from the existing and emerging social media innovations for increased agricultural productivity.

\section{METHODOLOGY}

Study area and design: This study was carried out in Thika Sub-County, an administrative unit of Kiambu County in central Kenya region. Thika Sub-County comprises of five agricultural wards namely Ngoliba, Hospital, Kamenu, Township, and Gatuanyaga. The wards are further categorized into urban, peri-urban and rural setups. To ease agricultural extension service delivery, farmers in the wards have been organized into small extension groups. Some of the groups were formally registered under the social development department while others were in the process of registration. The groups were heterogeneous in composition and membership size. A formal survey entailing face to face administration of a semi-structured questionnaire was conducted where quantitate data were generated. The research team under the leadership of the extension service providers in every ward visited the farmers during their scheduled group meetings thus enabling interactive sessions. The data were subjected to Analysis of Variance (ANOVA) using the Statistical Program for Social Sciences (SPSS) version 20.0. Chi-square test for independence at a 5\% confidence level was used to establish relationships between the variables.

Sampling Technique and Sample Size: Thika SubCounty was purposively selected for two reasons, first due to the diversity of the farming community which is categorized into urban, peri-urban and rural farmers. Secondly, the study area lies within the environs of the researcher's agricultural research Institute hence the interest in understanding whether the farmers could use social media to access research results. Through the guidance of the Ward Agricultural Extension Officers and based on level participation in agricultural matters at the time of the study, two groups from each of the five wards were again purposively selected. The ten groups of heterogeneous membership selected from the five wards had a total of 218 members. To determine the sample size, the survey adopted 95 percent certainty level for estimating the true population value, 50 percent as the expected proportion of the population with the attributes of interest and 5 percent confidence interval, resulting in 139 farmers. Using Probability Proportional to Size (PPS) technique, a sample of 140 farmers was drawn from the 218 farmers of the 10 extension groups (Table 1). After establishing the number of farmers to be obtained from each of the ten groups, simple random sampling was used to select the actual respondents from the membership list.

Table 1. Probability Proportional to Size Sampling of Respondents.

\begin{tabular}{llccc}
\hline Ward & Group Name & Total population & \% Population & Sample size per ward \\
\hline \multirow{2}{*}{ Ngoliba } & Duke Farmers Group & 50 & 23 & 32 \\
& Ngoliba United Farmers self-help group & 25 & 11 & 16 \\
\multirow{3}{*}{ Hospital } & Happy Valley Farmers Group & 15 & 7 & 10 \\
& Nanasi Farmers Group & 15 & 7 & 10 \\
& Valley Land Self-help group & 20 & 9 & 13 \\
\multirow{2}{*}{ Kamenu } & Vision self-help Group & 20 & 9 & 13 \\
\multirow{2}{*}{ Township } & Athena Horticultural Self Help Group & 18 & 8 & 12 \\
& Karibaribi Farmers Group & 15 & 7 & 10 \\
& Athi Gravity Farmers Group & 20 & 9 & 13 \\
& Munyu Kio Farmers Group & 20 & 9 & 13 \\
\hline
\end{tabular}




\section{RESULTS AND DISCUSSION}

Socio-demographic characteristics of respondents: The target population was majorly smallholder farmers where the majority, 58 percent possessed less than one acre of land, 38 percent owning between 1 to 5 acres with only 5 percent having more than 5 acres (Table 2). Female farmers formed the majority of the respondents in the study area at 60 percent. This corresponds with a report that the participation of women in agriculture compared to men is higher in sub-Saharan Africa with over 50 percent reported in East Africa (SOFA \& Doss, 2011). The position is further supported by FAO, (2011) who confirm that the percentage share of women in agricultural activities in most rural setup of developing countries was higher than that of men.
The farming activities majorly involved middle-aged and elderly farmers where 69 and 11 percent were found to be in the 36-64 and over 65 years age brackets respectively, while only 20 percent fell under the youth category of 18-35 years (Figure 1). This is an indication that agriculture is yet to be attractive to the youth, a position held by Afande, Maina, \& Mathenge (2015) who view the poor state of youth involvement in agricultural activities in Kenya as a matter of great concern among various stakeholders including researchers and policymakers. The findings corroborate those by Oto \& Shimayohol, (2011) who in their study on the extension communication channels' usage and preference by farmers in Benue State, Nigeria reported minimal participation of youth in agriculture.

Table 2. Land size occupied by farmers.

\begin{tabular}{lcc}
\hline Land acreage & Frequency & Percent \\
\hline$<1$ Acre & 81 & 58 \\
$1-5$ acres & 53 & 38 \\
$>5-10$ acres & 5 & 4 \\
$>10$ acres & 1 & 1 \\
\hline Total & 140 & 100.0 \\
\hline
\end{tabular}

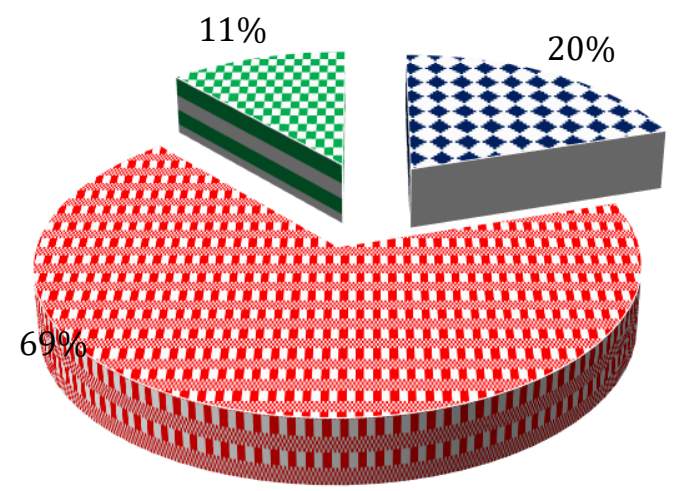

\$18-35 $36-64$ over 65

Figure 1. Frequency age distribution of farmers.

In terms of education (Figure 2), the study established that a vast majority of the farmers, 52 percent, possessed primary school level, 35 percent had secondary level with 9 percent having attained a tertiary level. However, a relatively small proportion of 4 percent did not have any formal education.

Level of social media familiarity: Though, a vast majority of farmers in the study area recorded some

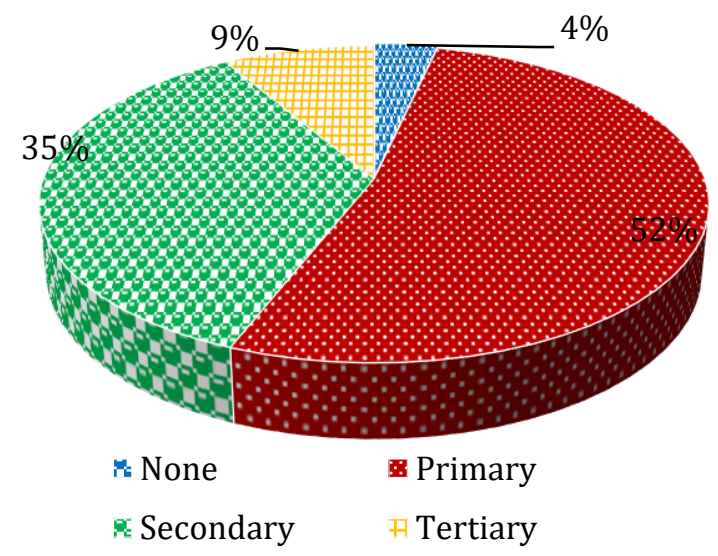

Figure 2. Distribution of farmers by education level.

degree of familiarity with social media only a small proportion had a high understanding. The illustration in Figure 3 shows that a relatively small population, 22 percent of farmers responded to being very well versed with social media, while a vast majority, 51 percent recorded superficial understanding.

A comparative 18 percent were completely ignorant of the technologies while 9 percent were not sure of their 
level of knowledge.

The study did not find any significant association $(p=0.17)$ between social media awareness and the three Sub-counties setups of urban, peri-urban and rural areas. This means that farmers in the target area were found to be more or less similar in terms of social media awareness irrespective of where they came from. However, as discussed below, both descriptive and inferential analysis revealed that education, age, and sex of the respondents played significant roles in influencing familiarity. More educated farmers registered a higher level of familiarity compared to those with little or no formal learning while younger farmers were found to be more familiar with social media compared to older farmers. Similarly, in relation to gender, men were also better versed than women.

Education and social media familiarity: A majority, 75 percent of farmers who had attained post-secondary education had a thorough knowledge of social media compared to 18 percent and 9 percent of those with secondary and primary education respectively (Figure 4). Correspondingly, all the farmers lacking formal education had never heard of social media. An analysis of association using Pearson Chi-Square revealed a significant difference (at $\mathrm{p}<0.007$ ) in familiarity with social media between farmers with higher levels of education compared the less educated (Table 3). This is further explained in Figure 5, which indicates that male respondents in the study area were more educated than their female counterparts constituting 82 percent of those who had attained tertiary education, 59 percent and 66 percent of those with secondary and primary levels respectively while only 18 percent had no formal learning. It is also worth noting that out of the youthful farmers, 74 percent had attained either secondary or tertiary education compared to 65 percent of those above 36 years thus explaining the reason why the age bracket recorded a higher level of familiarity.

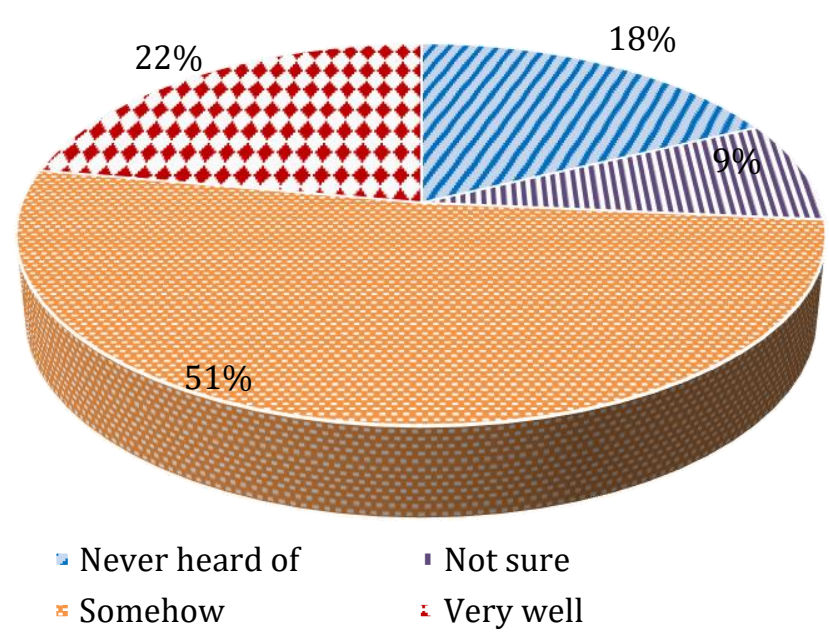

Figure 3. Level of familiarity with social media among farmers.

Table 3. Comparing respondents' education level and familiarity with social media.

\begin{tabular}{llccccc}
\hline & & \multicolumn{3}{c}{ Familiarity with Social Media } & Total \\
\hline \multirow{3}{*}{ Education } & & Never heard of & Not sure & Somehow & Very well & \\
& Not educated & 16 & 20 & 36 & 7 & 79 \\
Total & Educated & 4 & 14 & 25 & 18 & 61 \\
& & 20 & 34 & 61 & 25 & 140 \\
\hline
\end{tabular}




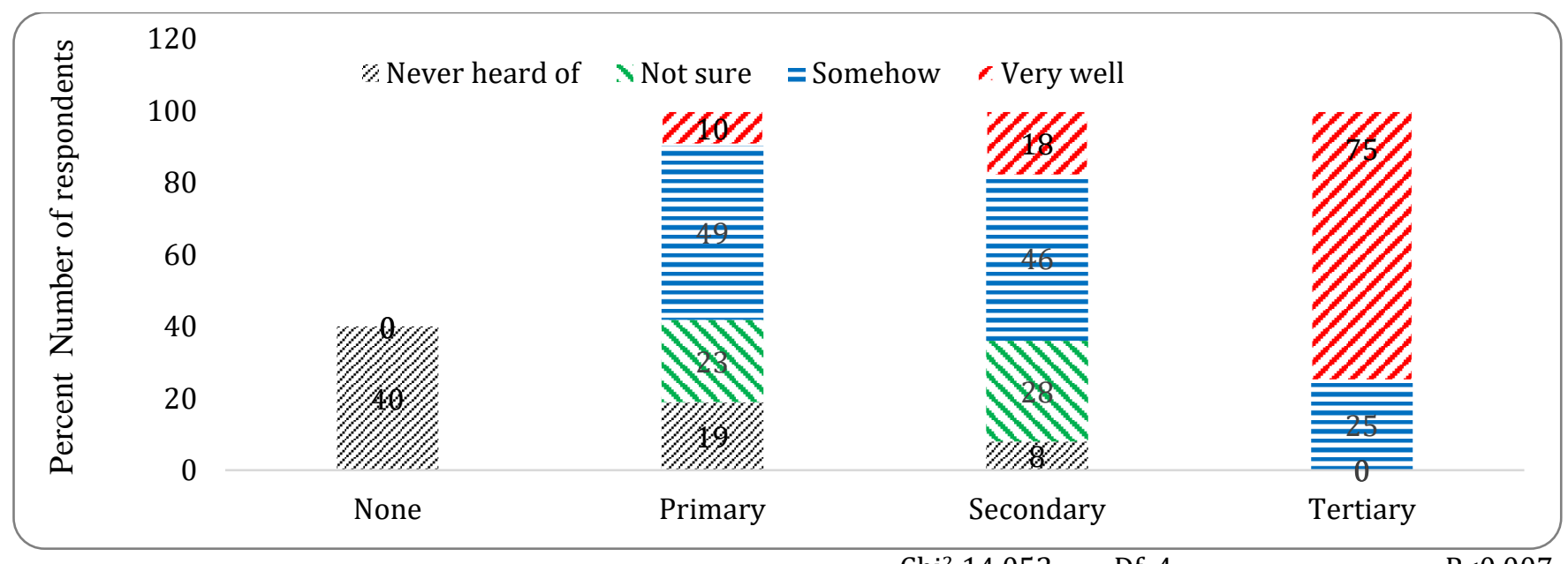

Figure 4. Comparing familiarity on social media with farmers' level of education.

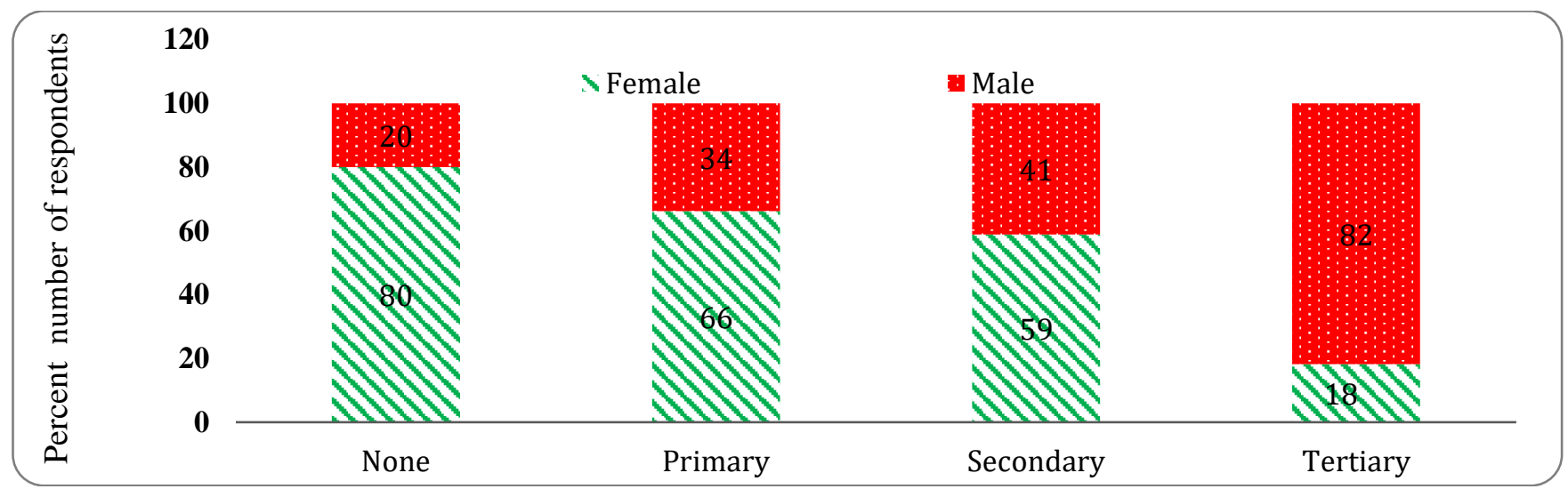

Figure 5. Comparing education level by sex of respondents.

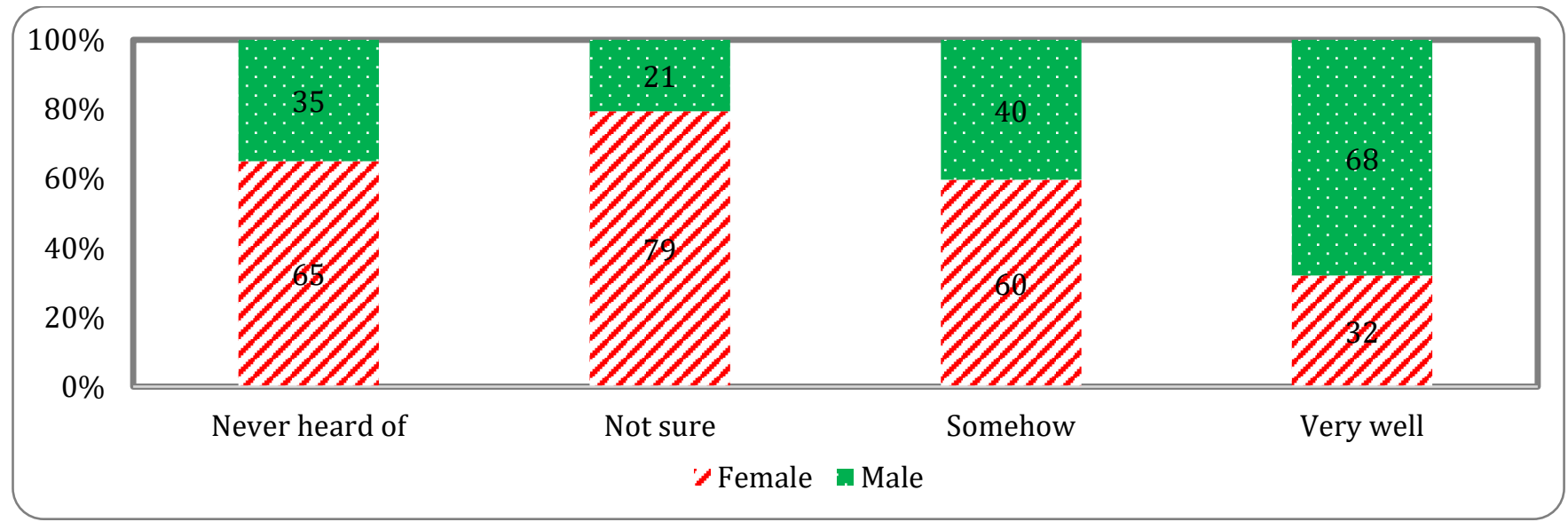

Figure 6. Comparing sex of respondent versus the level of familiarity with social media.

It is, therefore, appropriate to conclude that education is a key factor in influencing the levels of familiarity with social media among the respondents such that the as the level of formal learning increased the more knowledgeable they tended to be. It can, therefore, be interpreted that more educated farmers are likely to use 
social media more than those with lower levels of education. The men who are more educated and better versed with social media have a lower contribution to agricultural activities in the study area. The need to address the education gap while developing any initiatives to deploy social media in agricultural activities among this farming community cannot be overemphasized.

Gender and social media familiarity: Male farmers demonstrated a higher level of familiarity with social media at 68 percent compared to their female counterparts at 32 percent (Figure 6). Women further comprised the majority in the categories of farmers who had not heard of social media, those with superficial familiarity as well as the ones not sure of their knowledge at 65 percent, 60 percent, and 79 percent respectively.

Pearson $\mathrm{Chi}^{2}$ test confirmed that a significant positive relationship (at $\mathrm{p}<0.005$ ) existed between the sex of respondent and familiarity with social media where male farmers were found to be more familiar compared to the women as illustrated in Table 4.

The higher familiarity among the male respondents was further supported by the fact the men in the study area were more educated than women (Figure 5) considering that education had been found to have a positive influence social media knowledge level (Table 3).

Table 4. Comparing association between sex and familiarity with social media.

\begin{tabular}{llccccc}
\hline & & \multicolumn{3}{c}{ Awareness of Social Media } & \multicolumn{2}{c}{ Total } \\
\hline \multirow{3}{*}{ Sex } & & Never heard of & Not sure & Somehow & Very well & \\
& Female & 13 & 27 & 36 & 8 & 84 \\
Total & Male & 7 & 7 & 25 & 17 & 56 \\
& & 20 & 34 & 61 & 25 & 140 \\
\hline
\end{tabular}

$\mathrm{Chi}^{2}, 14.658 \quad$ Df, $4 \quad \mathrm{P}<0.005$.

Despite women forming the vast majority of the farming population in the study area, their level of social media familiarity appeared below than men. This, therefore, calls for special attention towards awareness among women to ensure that the farming community leap-frogs from the existing and emerging social media agricultural related initiatives considering that contribution women to agriculture is higher than that of men.

Age of farmers and social media familiarity: The study identified age as an important factor in determining the farmers' level of familiarity with social media. Younger respondents recorded a higher level of social media familiarity as opposed to older ones as shown in Figure 7 where 44 percent of those in the 1835 years category and 13 percent of the ones in 36-54 year bracket responded to being very well versed with social media. Conspicuously, none of the respondents above 65 years portrayed a high level of familiarity with the farmer category recording the highest proportion 29 percent, of those who had not heard of social media. Evidently, familiarity on social media seemed to decrease as the age of respondent increased. As illustrated in Figure 7, 44 percent of the farmers belonging to 18-35 age bracket exhibited a high level of social media familiarity compared to only 13 percent of those between 36 and 64 years and zero percent of those above 65 years. This is further confirmed through a test of relationships using Pearson Chi-Square which established a significant positive association between age and familiarity with social media (at $\mathrm{p}<0.001$ ) where the younger farmers were found to possess a higher level of knowledge compared to the older ones (Table 5).

Table 5. Relationship between farmer age and familiarity with social media.

\begin{tabular}{lcccccc}
\hline & \multicolumn{4}{c}{ The familiarity of Social Media } & \multicolumn{2}{c}{ Total } \\
\hline \multirow{3}{*}{ Age } & & Never heard of & Not sure & Somehow & Very well & \\
\cline { 2 - 6 } Total & 0 & 5 & 9 & 13 & 27 \\
\hline & Older & 20 & 29 & 52 & 12 & 113 \\
& & 20 & 34 & 61 & 25 & 140 \\
\hline
\end{tabular}




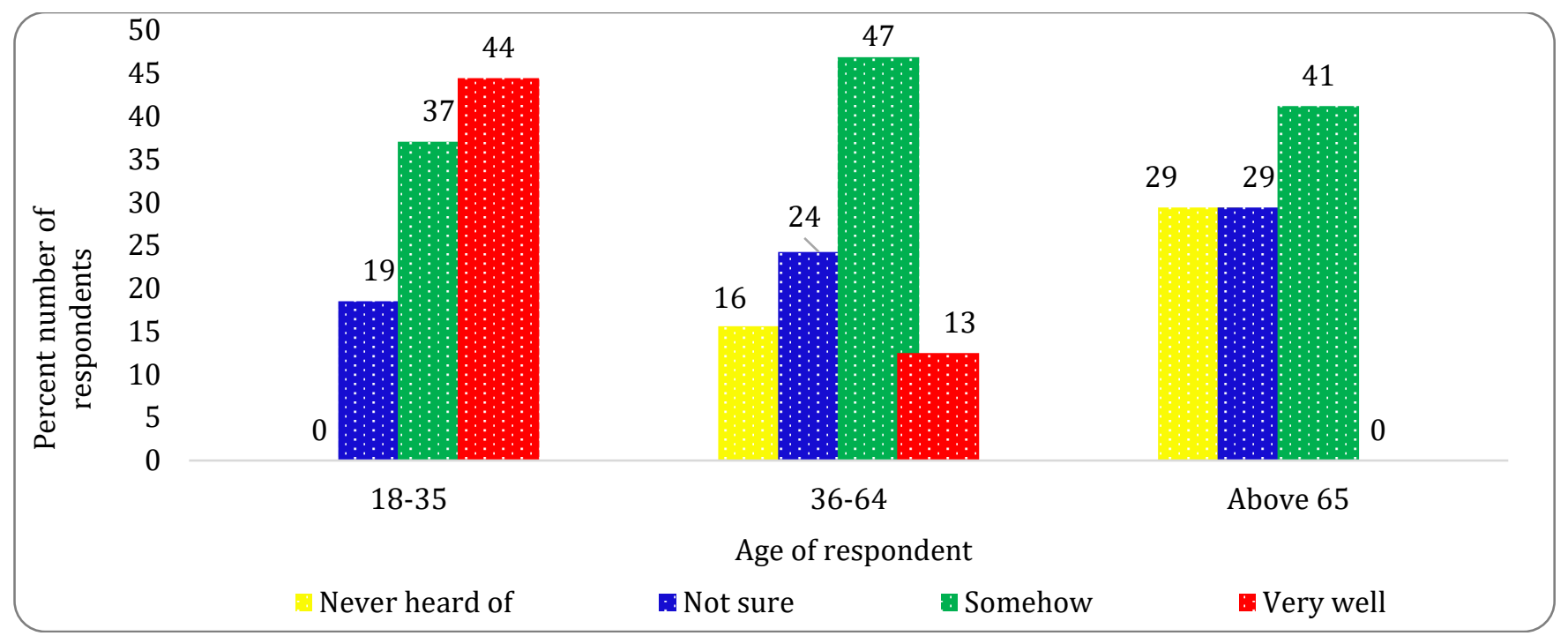

Figure 7. Comparing social media familiarity with the age of respondent.

Farming activities in the study area are majorly carried out by the older people, their limited knowledge on social media obviously prevents them from benefitting from the dynamic technologies. It is therefore important for agricultural extension stakeholders in the study area to put in a lot of effort in educating this key category of farmers on how to utilize social media to enable them real-time access to useful information for their daily activities. On the other hand, the youth who are well versed with social media participate less in agricultural related activities. The high level of social media familiarity among the young people could be tapped to attract more youth to agricultural activities through the promotion of the existing social media innovations as well participatory development of new programmes that are friendly to this category of farmers.

\section{CONCLUSIONS AND RECOMMENDATIONS}

Social media has been around and taking the communication industry by storm for about two decades. The technologies have demonstrated their impact on the promotion of extension programs by facilitating real-time interaction with clients, enabling outreach to new audiences, and promoting the development of relationships among actors in the agricultural sector ( (Cornelisse, Hyde, Raines, \& Kelley, 2011). However, social media familiarity among the smallholder farmers in the study area is limited thus denying the farming community the benefits associated with the robust technologies. Education, age, and gender greatly influence social media familiarity among farmers. More educated respondents recorded a higher social media familiarity level, and so did the younger farmers in relation to the older one. The men were also better versed compared to women. Social media awareness campaigns and other initiatives targeting rural areas are highly recommended to increase technology literacy among farming communities. Such efforts could only be successful if the farming community was segmented by education, age, and gender to ensure that social media needs of all the farmers are addressed. Particular attention on the awareness creation should be directed towards women who form the bulk of the farmers but unfortunately have been found to be with minimal knowledge on social media. Participatory youth friendly farming programmes could be designed and implemented through social media platforms to attract this category of farmers to agriculture. Training smallholder rural farmers who dominate the agricultural sector in Kenya on the importance of social media gives them a voice and an opportunity to be able to directly connect with the relevant stakeholders in agriculture thus enhancing access to critical information and technologies for increased productivity.

\section{ACKNOWLEDGEMENTS}

The Thika Sub-County Extension Agents, my three enumerators, and all the survey respondents are greatly appreciated for being instrumental during the fieldwork.

\section{REFERENCES}

Afande, F. O., Maina, W. N., \& Mathenge, P. M. (2015). Youth Engagement in Agriculture in Kenya: Challenges and Prospects. Journal of Culture, Society, and Development, 7. 
Andres, D., \& Woodard, J. (2013). Social Media Handbook for Agricultural Development Practitioners. The U.S. Agency for International Development.

Chisenga, J., Kedemi, R., \& Sam, J. (2014). The Use of Social Media in Agricultural Research Workflows in Ghana and Kenya. An International Journal For Information Specialists In Agriculture, Natural Resources, And The Environment, 48-57.

Cornelisse, S., Hyde, J., Raines, C., \& Kelley, K. (2011). Entrepreneurial Extension conducted via social media. Journal of Extension,, 49(6).

FAO. (2015). Retrieved from Food and Agriculture Organization: http://www.fao.org/nr/researchextension-systems/res-home/en/

Food \& Agriculture Organization. (2011). Women in Agriculture: Closing the gender gap for Development. Rome: Food and Agriculture Organization of the United Nations, ISBN 978-925-106768-0.

GoK. (2012). National Agricultural Sector Extension Policy (NASEP). Agricultural Sector Coordination Unit (ASCU).

Jijina, C. K., \& Raju, G. (2016). Social Media and Farmers. International Journal of Research in Engineering and Technology. KALRO. (2017). Strategic Plan 2017-2021. Nairobi: Kenya Agricultural and Livestock Research Organization, ISBN: 978-996630-032-4.

Kipkurgat, T., Onyiego, M., \& Chemwaina, S. (2016).
Impact of Social Media on Agricultural Extension in Kenya: A Case of Kesses District. International Journal of Agricultural Extension and Rural Development Studies,. 3, 1, 30-36.

KIPPRA. (2017). Kenya Economic Report: Sustaining Kenya's Economic Development by Deepening and Expanding Economic Integration in the Region. Nairobi: Kenya Institute for Public Policy Research and Analysis.

Oto, J. O., \& Shimayohol, D. (2011). Extension communication channels' usage and preference by farmers in Benue State, Nigeria. Journal of Agricultural Extension and Rural Development, 3(5), 88-94.

Rhoades, E., \& Aue, K. (2010). Social agriculture: Adoption of social media by agricultural editors and broadcasters. Paper presented at 107th Annual Meeting and Conference of Southern Association of Agricultural Scientists. Orlando, Florida.

SOFA \& Doss. (2011). The role of women in agriculture. ESA Working Paper No. 11-02. Agricultural Development Economics Division. Rome, Italy: The FA) of the United Nations.

Wabwoba, M. S., \& Wakhungu, J. W. (2013). Factors affecting the sustainability of community food security projects in Kiambu County. Agriculture \& Food Security, 2:9.

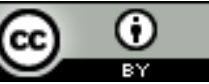

